\title{
Project Pandora: Student Teaching And Learning (Resources) Tool Box
}

\author{
Mark Loves, University of Wollongong, Australia
}

\begin{abstract}
Feedback from post graduate domestic and international students has highlighted the difficulties many have in coping with academic expectations of critical analytical thinking, reading and writing skills, academic language, referencing and expectations surrounding plagiarism and assessment. Many international students indicate that these concepts are unique to Australian tertiary institutions and that they struggle with their application. For these reasons, in late 2007 under the auspices of a Law Faculty Scholarship, the Centre for Transnational Crime Prevention (CTCP) commenced collaborative work with the University of Wollongong's Centre for Educational Development and Interactive Resources (CEDIR), the Learning Development Support Centre, the University Library, Information Technology Section (ITS) and the Student Equity and Diversity Liaison Office (SEDLO) to develop an online student teaching and learning (resources) toolbox. The objective of this program was to promote student skills development in critical areas of learning and facilitate delivery of support services to students, particularly those studying overseas. Early indications are that the program is being well received by students (both domestic and international), and that it has had a significant impact on improving academic literacy and lowering the levels of plagiarism detected within the targeted student populations.
\end{abstract}

Keywords: Critical analytical thinking, reading and writing skills, academic language, referencing, plagiarism, academic literacy, culturally conditioned, operant conditioning, social cognitive learning, Project Pandora, Centre for Transnational Crime Prevention.

\section{INTRODUCTION}

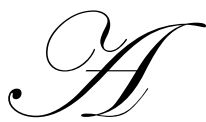

cademic literacy can be regarded as the ability to read, write, understand, analyse, interpret, create and communicate in a formal scholarly post secondary educational context. For many years now, the problems faced by first year post graduate domestic and international students in attempting to make a transition into university study have been well recognised. These problems and issues can generally be grouped within three specific categories; the requirements of students, the ability and motivation of teachers and the availability and quality of transition courses and programs.

There have been a number of studies into the social and cultural adjustments required of international students and the implications for their studies and well being. Edmond (1997) explored these difficulties, identifying important implications in terms of students grades and well being, where lack of familiarity with accepted academic convention, social rules, values and relationships may affect the attainment of educational goals . This is particularly true where students may be operating from a culturally conditioned basis, where behaviours and habits that may have been tolerated in their home countries are no longer tolerated in their adopted one (Mak, Westwood, Ishiyama \& Barker, 1999). There is much evidence that this adjustment to cultural and academic expectations can cause considerable stress to the students and may impact broadly upon their perceptions of learning in an Anglo western context (Barker, Troth \& Mak, 2002; Ballard \& Clanchy, 1984; Channell, 1990; Elsey, 1990; Ward \& Kennedy, 1993). Many international students will be overwhelmed by the demands and challenges of university life in a new country and this unfamiliarity with the host institution and it's expectations can cause considerable anxiety (Pedersen, 1991; Stening, 1979; Gudykunst \& Hammer, 1983). 
According to Barker, Child, Gallois, Jones, \& Callan, (1991), many of these transition problems are often over-attributed to English language difficulties when the real problems being experienced by the student are more related to their adapting to the cultural and academic expectations of their host institutions and communities. These difficulties can often be traced to a lack of coaching, practice and correction opportunities and the need for validation from both peers and teachers (Mak, et al. 1999).

Delpit (1988) argues that teachers have a responsibility to teach what he terms "the codes of power", that is, those expectations and competencies that the student is required to demonstrate to achieve success in a particular teaching and learning context. He maintains that if this is not achieved, then mismatched expectations will lead to student failure. Chanock (2008) supports this assertion in maintaining that these expectations need to be spelled out to students at an early stage of their studies to allow for a change of mind set. She discusses a particular case in which a Chinese student revealed that his key to academic success was not so much "losing his Chinese self", but more creating an "English self".

Ivanic (1998) takes this further in stating that the expectations surrounding academic literacy and practice need to be "stated explicitly, but left implicit", including "what sort of evidence or authority should be called upon, and in what circumstances". Without doubt, early student support programs, training and intervention have a great potential to assist both domestic and international students in their transition into new cultures and academic expectations, and teachers are the key to the delivery of this support.

The availability and quality of skills training and university transition courses and programs is another issue that has been popularly researched in recent years. There is a perception that universities do not afford time for academic skills training and that there is a real lack of training for new students (Chanock, 2008). It is argued that even where these academic bridging courses are delivered, they are often little more than the provision of information resource material, that "improves knowledge, but does not improve skills." (Irvine, 1998). Whilst there is some evidence of institutions embracing this type of training in recent times (see later in this paper), there has been little follow up research on the effectiveness of such training.

Mak, et al. (1999) claim that to be effective and reap maximum benefit from these skills courses and transition training, international and domestic students should be grouped together to assist in the establishment of interpersonal relationships and provide avenues for communication with mainstream students and teachers. This provides new students (both domestic and international) with the opportunity to seek mutual validation from their peers and teachers, in an environment where normally they might struggle with language and cultural handicaps. Both domestic and international students can appreciate their common struggles and frustrations with academic literacy skills and assist each other in the transition process. There is much evidence that this peer and teacher support is of great benefit, not only to international students, but to their domestic counterparts as well, as all students entering a discipline will struggle with new skills and concepts (Chanock, 2008; Barker, 1993; McInnis \& James, 1995; Westwood \& Ishiyama, 1991).

There are two major theories that strongly influence studies in this genre. The first is operant conditioning, which is the use of consequences to form or modify student behaviour (Skinner, 1972). Its benefits are well acknowledged and widely applied in many scientific and educational settings. Mak, et. al. (1999) discuss operant conditioning and the conditions under which it can be successful. One of these conditions is the, "provision of coaching and opportunities for practice to facilitate corrective feedback and perfection of new skills". It was with this condition in mind that the skills program, which is to be outlined later in this paper, was developed.

The other theory that strongly influenced the program was Bandura's (1977) social cognitive learning theory, which explains how students acquire and maintain particular behavioural patterns. Mak, et al. (1999) apply this theory to the transitioning of students to academic life and the acquiring of academic literacy skills. If new students are shown what to do and how to do it by credible role models, and given explanation and rationale for why a particular behaviour or action is required, then they are more likely to master that skill and perform that action when the need arises. 
A number of programs are currently being run within Australian universities to assist with new student skills development, which borrow from these theories. Whilst this list is not all encompassing, it does cover some of the major projects currently being conducted within Australian educational institutions.

1. The Griffith University (Queensland Australia) has developed its ExcelL Program (excellence in experiential learning and leadership) which is a major component of their orientation program offered to post graduate students each semester, designed to teach socio cultural competencies for academic and career success (Barker, Troth \& Mak, 2002).

2. In 2007/08, the Victoria University (Melbourne) were awarded \$80k from the Australian Teaching and Learning Council (formerly the Carrick Institute) to conduct research into the use of multi media resources and technologies to help Chinese students better understand the principles and issues of academic literacy and plagiarism. This is an extension of work undertaken as a pilot project in 2006.

The author was invited to attend and present at the most recent phase of this project, which was a miniconference/workshop held in August 2008 at their Melbourne city campus. The purpose of the workshop was to gain insight into issues surrounding academic literacy and teaching Chinese students from a 'reference group' of academics who have experience in these issues.

3. The MASUS (Measuring the Academic Skills of University Students) program is run by the Sydney University and is designed around diagnostic assessment of student writing skills. It assesses the ability of new students to read and write on particular disciplines or subject areas in a reasoned and analytical way, and then assesses their remedial training requirements from an examination of the results (Jones, 2008).

4. Finally the University of Wollongong's Centre for Transnational Crime Prevention has developed its student and learning (resources) tool box, a program which is further described in the next part of this paper.

\section{PROJECT PANDORA}

Transnational crime is an insidious and expanding side effect of globalisation, and has become increasingly sophisticated through employing new global networks, knowledge, skills, technologies and methodologies. The Centre for Transnational Crime Prevention (CTCP), Faculty of Law, University of Wollongong (Australia) was established in 2000 in response to this global threat. This research and teaching Centre was designed to focus on organised criminal activities that impact regional and global security, including narcotics production, trafficking of firearms and people, smuggling, terrorism, fraud \& money laundering, corruption, cyber crime, paedophile activity, natural resources poaching, illegal shipment of hazardous waste and identity theft. The Centre was founded on the concept that the operational, jurisdictional, legal and political complexities of transnational crime required a multi disciplinary response. The Centre boasts two flag ship degree courses, the Master of Transnational Crime Prevention (MTCP) and the Master of Laws in Prosecutions (LLM), which attract a variety of domestic and international students, particularly from the Asia / Pacific region.

Project Pandora was developed as a result of the identification of a number of issues that had arisen in relation to supporting international students at the CTCP. The major issue initially, was how to deliver student support services for courses that the Centre was proposing to deliver in China. A variant on this issue arose shortly after, involving international students enrolled in the MTCP. Feedback from post graduate domestic and international students highlighted the difficulties many were having in coping with university expectations of critical analytical thinking, reading and writing skills, academic language, referencing and expectations surrounding plagiarism. Many (international) students maintained that these concepts were unique to Australian tertiary institutions and that they were struggling with their application. Supporting these assertions, the CTCP had seen a growing trend in plagiarism, particularly amongst students studying offshore. Difficulties experienced with critical analytical skills were also obvious in the standard of assignments being submitted. 
For these reasons, in late 2007 (under the auspices of a Law Faculty service agreement) the CTCP commenced collaborative work with CEDIR, Learning Development, ITS, Library and SEDLO to develop an online Student Teaching and Learning (Resources) Toolbox, to promote student skills development in these areas and facilitate delivery of support services to students, particularly those studying overseas. A significant aspect of the project design was to assess the student's capability in these key skills through online (auditable) skills tests, thereby providing indication to subject coordinators that particular students require supplementary attention, and also to provide those coordinators with an auditable record should academic misconduct occur within the particular cohort assessed. The objectives of the project can be summarised as follows:

Developing learning and student support resources that can be used to cost effectively:

- $\quad$ facilitate delivery to international students domiciled overseas;

- $\quad$ provide for induction and orientation for international students domiciled in Australia;

- $\quad$ provide a feedback mechanism for tutors and subject coordinators;

- $\quad$ provide a compliance tool to ensure that students understand their academic obligations; and

- $\quad$ provide resources that can be implemented and adapted across the Law Faculty, and (potentially) the University.

The overall design and functionality of the Project Pandora on line resources tool box was adapted from a concept developed for the University of Wollongong Dubai campus, and included modules covering academic expectations, research (and analysis), academic reading and writing. These resources were provided to assist students in getting started in their studies whilst also providing a useful guide and overview to University life, services and facilities (including student support mechanisms). The toolbox was designed to engage students in learning activities, quizzes and questionnaires to facilitate their learning, and encourage them to be self reflective about their obligations in partnership with the CTCP, the University and their fellow students.

The training was delivered through facilitated two day workshops with post workshop participant surveys conducted to assess the value and success of the programs. Mid semester follow up sessions were then conducted for students requiring remedial work (although invitations were issued for the whole cohort to attend). Pilot programs were delivered in Australia (University of Wollongong) and in Malaysia (Judicial and Legal Training Institute ILKAP) in early 2008. Subsequent sessions were delivered interstate (Adelaide, South Australia), and again in Wollongong for MTCP and LLM students enrolling in second semester studies for 2008.

\section{THE STUDENT (RESOURCES) TOOLBOX}

The Project Pandora Student (Resources) Toolbox comprises a welcome page and four distinct modules, designed to address specific skill and knowledge areas identified as critical to student success and transition. The 'Expectations' module provides students with an outline of what they have to do to meet the expectations of the host institution including what to do when they encounter a problem and developing their ability to become self sufficient in their studies. Students are made aware that university study can build the foundations for a life time of learning and growth, provided they take responsibility for their own learning. The rewards are described as an enhanced ability to think, to solve problems, to connect and integrate knowledge and develop experience. Specific subject areas covered in this introductory module include: graduate quality outcomes; English language requirements, assessment and grading information; academic misconduct and its repercussions; time management; student academic grievance procedures; university policies; e-learning and on line services ${ }^{1}$.

Having covered university expectations, the students then undertake the research module. This module introduces the students to the research process and its importance in their studies. Conducted by professional senior librarians, the module introduces students to the materials, skills and processes they will require for researching International and Australian sources, both online and from within the library environment. It assists students by providing them with hands on practice in accessing International and Australian legislation, case law, and treaties,

\footnotetext{
${ }^{1}$ The Expectations Module can be accessed at http://ctcp.uow.edu.au/resources/Module_1/index.html
} 
accessing International and Australian journal articles, and assists them to feel confident in the use of electronic resources ${ }^{2}$.

The next part of the program undertaken by students is the reading module. In this part of the program students are advised that as part of their studies, they will be expected to do a wide variety of reading, including academic journal articles, government reports, international treaties and policies. The module is delivered by university learning development professionals who tutor students on reading strategically and critically, encouraging them to think about what they are reading, to ask questions, make notes and identify links between what they are reading and what they need to use in their assessment tasks. In this part of the program they are trained on the use of mind maps, note taking (Cornell method), skim reading and evaluating sources ${ }^{3}$.

The final part of the program undertaken by students is the writing module. This part of the program is again delivered by learning development professionals, who tutor the students on different aspects of academic writing. Initially, the students are schooled on understanding the difference between description, explanation and argumentation and to understand the text composition process. The students are then prompted to consider a range of evidence, form clear opinions and to organise their textual product according to the established pattern or 'logic' of academic essays. The students then undertake specific written activities designed to help them practice the skills of carefully summarising, paraphrasing and referencing the words of others, whilst at the same time writing concisely and coherently and expanding their vocabulary. Specific skills covered in this module include speed writing, argumentation, written 'voice', academic style and legal citation ${ }^{4}$.

\section{WOLLONGONG PILOT}

The initial two day pilot program was conducted at the University of Wollongong from the 29 February - 1 March 2008. Following the completion of the sessions, the students were asked to evaluate the program through an on line survey. Since the questionnaire was to be self administered, the questions were structured as close-ended to improve simplicity of analysis. As a result, the Likert scale format was chosen as it is easily converted to generic scores for data analysis. The survey consisted of 18 questions, two of which invited free text responses. Prior to the application of the survey, feedback was elicited from individuals experienced in survey design. The survey was also reviewed by CEDIR, to assess the relevancy, clarity and context of the questions. The results of the survey are set out in 'Appendix A' to this paper. For the Wollongong pilot, respondent demographic and educational details were as follows:

- $\quad$ in total, 27 responses were received;

- $\quad 16$ of the respondents were male (59\%) and 11 were female (41\%);

- 9 different nationalities were represented across the respondents (15 Australian, 4 Chinese, 1 Thai, 1 Bulgarian, 1 Tongan, $1 \mathrm{Ni}$-Vanuatu, 1 Indonesian, 1 Saudi and 2 Pakistani);

- the ages of the respondents ranged from $20-30$ years $(10,37 \%), 31-40$ years $(14,52 \%)$ and $41-50(3$, $11 \%)$;

- $\quad 89 \%$ (24) of the respondents had previously studied at University, whilst $11 \%$ (3) respondents had no prior university experience;

- $\quad$ of the 24 respondents with prior university experience, 15 had studied within Australia whilst 9 had studied overseas;

- $\quad$ whilst the majority had studied at under graduate level, one respondent had studied at post graduate (masters) level.

In the Wollongong survey, students were prompted to nominate what they liked most, and least, about the program. Some students commented on their lack of previous academic literacy training:

\footnotetext{
${ }^{2}$ The Research Module can be accessed at http://ctcp.uow.edu.au/resources/Module_2/index.html

${ }^{3}$ The Reading Module can be accessed at http://ctcp.uow.edu.au/resources/Module_3/index.html

${ }^{4}$ The Writing Module can be accessed at http://ctcp.uow.edu.au/resources/Module_4/index.html
} 
I have never been provided information with regards to research, reading and writing academically so this was of great benefit to me;

It gave me a good insight into what I need to do to research, write and how to structure my essays. It has been about 10 years since I have done any research, so it was helpful in bringing me up to speed in technology and research;

The most interesting part is the referencing system which is totally different from what I have learned before, and I have to apply all the rules strictly during my academic study.

However, others thought that the chance to network with their peers and lecturers was most valuable:

It was also good to be able to meet and network with other students and CTCP staff, it was good to have the opportunity to ask questions and understand the expectations of the course;

.......... good refresher to university studies, presentations were provided by knowledgeable lecturers.

Some respondents complained about the length of the program:

Research modules. I think these could have been shortened substantially;

The second day could have been done (sic) in about half the time (there seemed to be a fair amount of sitting and waiting);

Day 2 was drawn out and very repetitive, I felt that the material we covered could have been condensed into a couple of hours.

Whilst others complained of a lack of time to complete the course content:

.what I like least is the time arrangement of the course since it is a little bit intensive;

Since I've never taken any English course for academic purpose, I found it quite difficult to gather every (sic) information as this is just a 2-day course and there are still many (sic) information I've missed;

..........two day duration of the course was perhaps not sufficient for such so many topics, very busy schedule.

\section{MALAYSIA PILOT}

The Malaysian two day pilot program was conducted at the Judicial and Legal Training Institute (ILKAP) which is the training center for prosecutors attached to the Malaysian Attorney General's Department. The program was conducted 26 - 27 March 2008. Following the completion of the sessions, the students were again asked to evaluate the program through an on line survey, under the same conditions as the survey conducted earlier that month in Wollongong. The results of the survey are set out in Appendix B to this paper. Respondent demographic and educational details were as follows:

- $\quad$ in total, 16 responses were received;

- 5 of the respondents were male (31\%) and 11 were female (69\%);

- $\quad$ all respondents were Malaysian prosecutorial students;

- $\quad$ the ages of the respondents ranged from $20-30$ years $(6,38 \%), 31-40$ years $(9,56 \%)$ and $41-50(1$, $6 \%)$

- $\quad 75 \%$ (12) of the respondents had previously studied at University, whilst 25\% (4) respondents had no prior university experience;

- $\quad$ of the 12 respondents with prior university experience, all had completed their studies in Malaysia;

- $\quad$ of these, all 12 had studied at under graduate level (LLB).

In the Malaysian survey, students were prompted to nominate what they liked most, and least, about the program. The students commented on the interactiveness of the program:

Sets of exercises given provide more understanding on the topics;

Interactive nature of the programme. Students invited to participate. Relieves boredom; 
The hands-on approach to the work and clear explanations of the subject matter and new perspectives;

........interactive sessions and presentations. Clear examples are shown as to the correct method for referencing and the importance of avoiding plagiarism.

Whilst others commented on the value of experienced lecturers:

1. Experience lecturers. 2. Interactive sessions. 3. Valuable and interesting information;

The lecturers are very helpful and the exercises are very good.

The main complaint made by the Malaysian respondents was that the two day course was too short to absorb the amount of information taught during the program;

The lack of time to digest certain lessons;

........too short of a time given to grasp difficult topics;

........too much information to be digested in just 2 days. I would suggest the course be extended to $21 / 2$ or 3 days;

The sheer amount of material covered appears daunting at the very least and insanely incomprehensible by the ordinary human mind at the very worst. It makes me wonder whether I will be able to actually complete this course.

\section{$2^{\mathrm{ND}}$ WOLLONGONG PROGRAM}

Taking into account the feedback from the pilot programs in both Wollongong and Malaysia, the program was amended accordingly to provide more time for discussion and more interactive exercises regarding the academic literacy modules. One full day was allocated to the reading and writing modules, where previously, only half a day had been allocated. All modules were also relocated to a computer laboratory within the University, so that each student could practice what was being taught during the research sessions, rather than merely observing its demonstration.

The $2^{\text {nd }}$ Wollongong program was conducted at the University of Wollongong from the $25-26$ July 2008. Following the completion of the sessions, the students were again asked to evaluate the program through an on line survey, under the same conditions as the surveys conducted earlier in both Wollongong and Malaysia. The results of the survey are set out in Appendix C to this paper. Respondent demographic and educational details were as follows:

- $\quad$ in total, 12 responses were received;

- 8 of the respondents were male (67\%) and 4 were female (33\%);

- 9 different nationalities were represented across the respondents (1 Australian, 2 Fijian, 2 Samoan, 2 Filipino, 1 Chinese, 1 Papua New Guinean, 1 Mongolian, 1 Vietnamese and 1 Ghanaian);

- $\quad$ the ages of the respondents ranged from $20-30$ years $(2,17 \%), 31-40$ years $(6,50 \%), 41-50(3,25 \%)$ and above $50(1,8 \%)$;

- $\quad 58 \%$ (7) of the respondents had previously studied at University, whilst $42 \%$ (5) respondents had no prior university experience;

- $\quad$ of the 7 respondents with prior university experience, 1 had studied within Australia whilst 6 had studied over seas;

- whilst the majority had studied at under graduate level, one respondent had studied at post graduate (masters) level.

As in the previous surveys, students were prompted to nominate what they liked most, and least, about the program. The respondents commented on the value of the course and its content:

Assisted me to learn (sic) where I could obtain proper assistance/information in relation to referencing and research. Provided the names (and faces) of people who are willing to help (something I did not access in my previous studies); 
That it was face to face teaching with all students having access to information provided and assistance by lecturers.

That it also created in a forum style of teaching both student and lectures (sic) participated which allow us to ask questions on particular issues at the time of lecturers;

......... it was a great opportunity given to learn how to guide my study and be able to meet the requirements needed by the University;

The content of this course in totality is an eye opener to achieve good marks in the course work ahead. The skills course has taken away the clouds of uncertainty and doubts. It has shown the direction towards the wealth of knowledge available to successfully complete studies.

As in the previous surveys, complaints mainly centred on a lack of time scheduled for the program:

Time frame of the course ... it would have been nice if it was a three days course;

........... therefore I think 2 days are not enough to cover the whole scheme;

Limited time and some lecturers were fast in delivering their lectures;

There is too much information to me (sic). And too little time to digest and absorb all I accepted;

The two days workshop was really a good kick start to the subjects ahead but there needs to be more time given to properly digest the things taught;

I would suggest for group discussions to give an opportunity to those students who would prefer to express themselves in smaller groups and seek assistance from their peers;

Overall the workshop was a success and perhaps should be a pre-requisite workshop for all universities;

\section{CONCLUSIONS AND FUTURE WORK}

It becomes apparent from early survey results conducted in both Wollongong and Malaysia, that many students recognise the lack of availability of post graduate academic literacy training, particularly for those from international backgrounds or indeed, domestic students recommencing their studies after a long period away from university. Most students who undertook the program were supportive of it, and reported deriving great benefit from the course. The major criticism of the program made by students was that it failed to allow sufficient time for them to absorb the amount of information covered during the sessions, particularly impacted by the intensive style delivery of the course. However, some contradiction did emerge in this regard, as whilst time frames appeared to be a significant issue for international students, some domestic students actually complained about the length of the program.

One interesting aspect of the course was the grouping of both domestic and international students into the one program. Whilst this was not at issue with the Malaysian pilot, it was a major outcome of the Wollongong sessions. Student feedback supports prior academic research acknowledging that programs of this type are most beneficial (to both domestic and international students) where the students are grouped together, to assist in the establishment of interpersonal relationships and provide avenues for communication (Mak, et al., 1999).

International students (particularly the Malaysian students) appeared to appreciate the interactive nature of the program, and its opportunity to break away from the Confucianist education type, whilst at the same time valuing the status and experience of the lecturers used in its delivery. Overall, the program is considered a considerable success and remains an ongoing pre-requisite to intensive teaching models employed within both the MTCP and the LLB (Prosecutions). This success is evidenced by a $100 \%$ reduction in the levels of plagiarism detected amongst the subject student cohort, as well as a significant improvement in the standard of assessment items submitted, as evidenced through subject coordinator feedback. Aspects for future study include more acute examination of how the domestic / international student peer support networks are developed and maintained and how they assist student development and progression in post graduate studies.

\section{AUTHOR INFORMATION}

Mark Loves is a former Police Detective Sergeant with extensive experience in criminal investigation and intelligence. After the police, he embarked on a career in private sector Corporate Security and Risk Management, 
during which he was appointed by the Australian Attorney General to the Commonwealth Critical Infrastructure Advisory Council (CIAC), whilst achieving a National security clearance to 'Top Secret' level. He is a former lecturer at the University of Western Sydney, Charles Sturt University (Australia) and is currently a Senior Lecturer / Program Manager at the Centre for Transnational Crime Prevention, University of Wollongong, where he coordinates the Masters degree program.

\section{REFERENCES}

1. Ballard, B. \& Clanchy, J (1984) ‘Study abroad: A manual for Asian students', Longman Malaysia, Kuala Lumpa.

2. Barker, M. (1993) ' Perception of social rules in intercultural and intracultural encounters: A study of Australian and ethnic Chinese university students'. Unpublished Ph. D thesis. Department of Psychology, University of Queensland.

3. Barker, M., Child, C., Gallois, C., Jones, E., \& Callan, V. J. (1991) 'Difficulties of overseas students in social and academic situations,' Australian Journal of Psychology, vol.43, pp. 79-84.

4. Barker, M., Troth, A., \& Mak, A. (2002) Transition to a new academic context: intercultural skills raining for international post graduate students, published in Envisioning Practice - implementing change (Vol 1). Proceedings of the $10^{\text {th }}$ Annual International Conference on Post compulsory Education and training Gold Coast 2-4 December 2002, pp 90-96

5. Channell, J. (1990) 'The Student-Tutor Relationship', in The Learning Experiences of International students, M Kinnell, Open University Press, Buckingham, pp. 63 - 81.

6. Delpit, L (1988). 'The silenced dialogue: Power and pedagogy in educating other peoples children'. Harvard educational review 58, pp280 - 298.

7. Edmond, M. (1997), 'Social difficulties of international and Australian students,' Journal of the Australian and New Zealand Student Services Association, vol.10, pp. 16-37.

8. $\quad$ Elsey, B. (1990) 'Teaching and Learning', in The Learning Experiences of International students, M. Kinnell, Open University Press, Buckingham, pp. 46-62.

9. Gudykunst, W.B, \& Hammer, M. R. G. (1983). Basic training design: Approaches to intercultural training. In D. Landis \& R.W. Brislin (Eds), Handbook of Intercultural Training, Vol 1 (pp.118-154). New York: Pergamon.

10. Irvine, I. (1998), 'International Office Benchmarking Survey Report', Australian Government Publishing Service, Canberra

11. Ivanic, R., (1998) 'Writing and Identity: the discoursal construction of identity in academic writing'. Ansterdam: John Benjamins, p 277.

12. Jones, J. (2008) 'The MASUS procedure: retrospective and prospective'. Presented to NSW / ACT AALL Meeting, Learning Centre University of Sydney, 26 September 2008.

13. Mak, A.S., Westwood, M. J., Ishiyama F.I. \& Barker, M.C. (1999) 'Optimising conditions for learning sociocultural competencies for success'. International Journal of Intercultural Relations, Vol 23, No1. pp 77-90.

14. McInnis, C., \& James, R. (1995) 'First year on campus’. Canberra: Australian Government Publishing Service.

15. Pedersen, P. (1991) 'Counseling international students'. The Counseling Psychologist, 19, pp 10-58.

16. Skinner, B.F. (1972). 'Beyond freedom and dignity'. New York: Bantam.

17. Stening, B.W. (1979). Problems in cross-cultural contact: A literature review. International Journal of Intercultural Relations, 3, 269-313.

18. Ward, C. \& Kennedy, A. (1993) 'Psychological and socio-cultural adjustment during cross-cultural transitions: A comparison of secondary students overseas and at home', International Journal of Psychology, vol. 28, no. 2, pp. 129-140.

19. Westwood, M.J., \& Ishiyama, F.I. (1991). 'Challenges in counseling immigrant clients: Understanding intercultural barriers to career adjustment'. Journal of Employment Counseling, 28, pp 130-143. 


\section{NOTES}

